\title{
Comparison of reliability evaluation methods between China and Canada standards for wood structures featuring duration of load
}

\author{
Qiongyao Wu', Shuang $\mathrm{Niu}^{2^{*}}$ (D) and Enchun Zhu
}

\begin{abstract}
Duration of load (DOL) is a key factor in design of wood structures, which makes the reliability analysis of wood structures more complicated. The importance of $\mathrm{DOL}$ is widely recognized, yet the methods and models through which it is incorporated into design codes vary substantially by country/region. Few investigations of the effect of different model assumptions of DOL and other random variables on the results of reliability analysis of wood structures can be found. In this paper, comparisons are made on the reliability analysis methods that underlie the China and the Canada standards for design of wood structures. Main characteristics of these two methods, especially the way how DOL is treated are investigated. Reliability analysis was carried out with the two methods employing the same set of material properties and load parameters. The resulted relationships between reliability index $\beta$ and resistance partial factor $\gamma_{R}{ }^{*}$ (the $\beta-\gamma_{R}{ }^{*}$ curves) for four load combinations are compared to study the safety level indicated by the two methods. The comparison shows that the damage accumulation model (Foschi-Yao model) in the Canada analysis method is highly dependent on the type and duration of load, resulting in more conservative design than the China analysis method in loading cases dominated by dead load, but less conservative design in cases of high level of live loads. The characteristics of the load effect term of the performance function are also found to make considerable difference in reliability levels between the two methods. This study aims to provide references for researchers and standard developers in the field of wood structures.
\end{abstract}

Keywords: Wood structure, Reliability analysis, Duration of load (DOL), Damage accumulation model

\section{Introduction}

Following the general principles set out in ISO 2394 [1], most countries have adopted the reliability-based design method in their structural design codes. This method involves a concept of "limit state", which is a critical condition for a structure/member beyond which the relevant design criterion is no longer fulfilled. Two limit states, viz. the ultimate limit state and the serviceability limit state, are generally adopted, respectively, for structural safety and serviceability performance. Structural reliability represents the probability of a structure fulfilling its

\footnotetext{
*Correspondence: aniu216@126.com

2 Department of Civil Engineering, Harbin Institute of Technology at Weihai, Weihai 264209, China

Full list of author information is available at the end of the article
}

intended function without failure over the design reference period.

One feature of wood that distinguishes it from other structural materials (e.g., steel or concrete) is duration of load (DOL) [2], i.e., as the load on a wood member persists, the strength of the wood decreases with time. Only some of the many studies about DOL are mentioned below for a brief appreciation of the research history and the state-of-the-art progress. Ever since its discovery in 1740 [3], DOL has been widely studied by means of long-term experiments of strength of wood by researchers around the world [4-7]. Wood [8] proposed the first strength reduction curve, known as the Madison curve, by fitting a series of experimental data. This curve was purely empirical and was not reflecting the variability in DOL, but it effectively facilitated design practice 
and is still in use today in many design codes. Damage accumulation models [9-11] were later proposed which take account of the variability in DOL and allow it to be estimated given any arbitrary stress history in a member. Recently a model was also proposed [12] to better reflect the stochastic damage accumulation process in DOL. Existing models that treat DOL either as a random variable or as a stochastic process accommodate the need of covering it in reliability analysis of wood structures. However, current wood design standards in different countries differ considerably regarding whether a reliability basis is employed and the way how DOL is covered in reliability evaluation. For example, Canada and China wood standards both determine design strengths of wood on the basis of reliability analysis [13, 14], in which DOL is included as a random variable. The American standard has two design methods used in parallel, one being a reliability-based load and resistance factor design (LRFD) method of a similar reliability calibration process with Canada standard [15], and the other being an empirical allowable stress design (ASD) method (including the equivalent LRFD format equations converted from it). The European design code for wood structures (EC 5) also has a reliability basis [16].

Booming of wood structures around the world $[17,18]$ is stimulating international trade of wood products and international collaborations in timber engineering. For example, China has been importing huge volumes of wood products such as glulam, dimension lumber, woodbased structural panels and structural composite lumber from forest-rich countries like North America, Russia, EU and New Zealand, to meet the increasing demand for wood structures during the past two decades. The trend of international collaborations in wood structure engineering poses a potential necessity of comparison between design standards of different countries. Questions might arise such as which standard yields more conservative design, and how could their reliability level be compared? Since the assumptions and treatments of parameters involved in the reliability analysis of wood structures in different countries are quite different, it is of interest to investigate the influence of such assumptions and treatments as a fundamental step. Since Canadian lumber is most widely used in China and the lumber is incorporated into the national wood standard GB 50005 [19] via a newly conducted reliability analysis [14], this paper focuses on the reliability analysis methods, respectively, adopted by China and Canada standards for wood structures. Comparisons are made between the assumptions and treatments of related variables in the two reliability analysis methods, and the effect on safety level in the respective wood standard from the analysis methods investigated.

\section{Methods}

In this section, a review of the China and Canada reliability analysis methods is presented, with special attention paid to the detailed differences in the assumptions and treatments of all random variables (including the DOL factors). Parameters for reliability analysis and comparison are also discussed.

\section{The China reliability analysis method}

The design value of wood strength $f_{\mathrm{d}}$ in China standard GB 50005 [19] is expressed as $f_{\mathrm{d}}=f_{\mathrm{k}} K_{\mathrm{DOL}} / \gamma_{\mathrm{R}}$. Accordingly, the performance function for ultimate limit state reliability analysis was established by Zhu et al. [14] as

$$
Z=K_{\mathrm{A}} K_{\mathrm{P}} K_{\mathrm{Q} 3} f-\frac{f_{\mathrm{k}} K_{\mathrm{DOL}}(g+q \rho) K_{\mathrm{B}}}{\gamma_{\mathrm{R}}\left(\gamma_{\mathrm{G}}+\psi_{\mathrm{c}} \gamma_{\mathrm{Q}} \rho\right)},
$$

where $f$ is a random variable denoting the short-term strength of wood; $K_{\mathrm{A}}$ is a random variable accounting for uncertainty of the cross-sectional dimensions of wood member, defined as the ratio of actual cross-section property to the nominal value in resistance calculation; $K_{\mathrm{p}}$ is a random variable accounting for uncertainty associated with resistance prediction model, defined as the ratio of true resistance to that obtained from resistance prediction model; $K_{\mathrm{Q} 3}$ is a random variable accounting for DOL, defined as the ratio of long-term strength to shortterm strength of wood; $f_{\mathrm{k}}$ is the characteristic strength of wood, taken as the $5 \%$ fractile of the short-term strength $f ; K_{\mathrm{DOL}}$ is the DOL factor specified in the design standard, taken as the mean value of random variable $K_{\mathrm{Q} 3} ; \gamma_{\mathrm{R}}, \gamma_{\mathrm{G}}$ and $\gamma_{\mathrm{Q}}$ are, respectively, the resistance partial factor, dead load partial factor and live load partial factor; $\psi_{\mathrm{c}}$ is the combination factor for live load; $g$ is a random variable, defined as the ratio of actual dead load $G$ (random) to the characteristic value $G_{\mathrm{K}} ; q$ is a random variable, defined as the ratio of actual live load $Q$ (random) to the characteristic value $Q_{K} ; \rho$ is the ratio of characteristic live load to characteristic dead load, $\rho=Q_{\mathrm{K}} / G_{\mathrm{K}} ; K_{\mathrm{B}}$ is a random variable accounting for uncertainty associated with load effect calculation model, defined as the ratio of true load effect to that obtained from calculation model.

The two terms on the right-hand side of Eq. (1) represent resistance and load effect of a wood member, respectively. Equation (1) is applicable only to wood members loaded parallel to grain. The short-term strength $f$ of wood is assumed to follow a lognormal probability distribution. Its mean value $f_{\mathrm{m}}$, coefficient of variation (COV) $V_{\mathrm{f}}$ and the characteristic strength $f_{\mathrm{k}}$ comply with a relationship as

$$
f_{\mathrm{m}} / f_{\mathrm{k}}=\exp \left[1.645 \sqrt{\ln \left(1+V_{\mathrm{f}}^{2}\right)}\right] \sqrt{1+V_{\mathrm{f}}^{2}} .
$$


The mean value and $\mathrm{COV}$ of random variables $K_{\mathrm{A}}$, $K_{\mathrm{P}}, K_{\mathrm{Q} 3}$ and $K_{\mathrm{B}}$ are listed in Table 1 , for wood members under bending, compression and tension, respectively.

In the China standard, the following load conditions are distinguished for DOL: (1) load of normal duration such as office or residential floor live load, snow load and wind load, $E_{\mathrm{KQ} 3}=K_{\mathrm{DOL}}=0.72$; (2) temporary load such as construction load, $E_{\mathrm{KQ} 3}=K_{\mathrm{DOL}}=0.72 \times 1.2=0.864$; (3) load of long duration such as dead load-dominated cases when dead load contributes over $80 \%$ of the total load effect, $E_{\mathrm{KQ} 3}=K_{\mathrm{DOL}}=0.72 \times 0.8=0.576$.

With the performance function and parameters detailed above, reliability analysis for the China standard was conducted by employing first-order reliability method (FORM) for different load combinations [14].

\section{The Canada reliability analysis method}

For Canada wood standard CSA O86 [20], reliability evaluation is based on the research by Foschi et al. [13]. The reliability analysis was divided into two steps, viz. short-term analysis (DOL not included) and long-term analysis (DOL included). For short-term analysis, the performance function was established as

$$
Z=\sigma_{\mathrm{s}}-\frac{\phi \sigma_{0.05}}{\left(\gamma_{\mathrm{G}} r+\gamma_{\mathrm{Q}}\right)}(g r+q),
$$

where $\sigma_{\mathrm{s}}$ is a random variable denoting short-term strength of wood; $\sigma_{0.05}$ is the $5 \%$ fractile of $\sigma_{s} ; g$ is the ratio of actual dead load $G$ (random) to nominal dead load $G_{n}$; $q$ is the ratio of actual live load $Q$ (random) to the nominal live load $Q_{\mathrm{n}} ; r$ is the ratio of nominal dead load to nominal live load (reciprocal of $\rho$ in Eq. (1)), $r=G_{\mathrm{n}} / Q_{\mathrm{n}}$; $\phi, \gamma_{\mathrm{G}}$ and $\gamma_{\mathrm{Q}}$ are, respectively, the resistance factor, dead load factor and live load factor.

For long-term reliability analysis, the performance function was derived as Eq. (4), where $\alpha$ is the damage

\begin{tabular}{llll}
$\begin{array}{l}\text { Table } 1 \\
\text { in China analysis method } \\
\text { Parameter }\end{array}$ & Bending & Compression & Tension \\
\hline$E_{\mathrm{KA}}$ & 1.00 & 1.00 & 1.00 \\
$V_{\mathrm{KA}}$ & 0.05 & 0.03 & 0.03 \\
$E_{\mathrm{KP}}$ & 1.00 & 1.00 & 1.00 \\
$V_{\mathrm{KP}}$ & 0.05 & 0.05 & 0.05 \\
$E_{\mathrm{KQ} 3}$ & 0.72 & 0.72 & 0.72 \\
$V_{\mathrm{KQ} 3}$ & 0.12 & 0.12 & 0.12 \\
$E_{K \mathrm{~B}}$ & 1.00 & 1.00 & 1.00 \\
$V_{\mathrm{KB}}$ & 0.05 & 0.05 & 0.05 \\
\hline
\end{tabular}

Mean value and COV of a variable $K$ is denoted as $E_{\mathrm{K}}$ and $V_{\mathrm{K}}$, respectively. $E_{\mathrm{KQ} 3}$ is multiplied with a modification factor of 1.2 and 0.8 for construction load and load of long duration, respectively index representing the strength reduction due to DOL. Index $\alpha$ accumulates from 0 up to 1 , with $\alpha=0$ denoting no damage and $\alpha=1$ denoting failure of wood. Accumulation of $\alpha$ with time is at a rate expressed with Eq. (5), which is known as Foschi-Yao damage accumulation model [11]:

$$
\begin{aligned}
& Z=1-\alpha, \\
& \frac{\mathrm{d} \alpha}{\mathrm{d} t}=a\left(\frac{\sigma(t)}{\sigma_{\mathrm{s}}}-\eta\right)^{b}+c\left(\frac{\sigma(t)}{\sigma_{\mathrm{s}}}-\eta\right)^{n} \alpha(t),
\end{aligned}
$$

where $a, b, c, n$ and $\eta$ are model parameters; $\sigma_{\mathrm{s}}$ is the short-term strength of timber; $\sigma(t)$ is the applied stress as function of time $t ; \eta$ is a threshold stress ratio below which damage is assumed not to be incurred by the applied stress; $\alpha(t)$ is the damage index at time $t$. Model parameters $a, b, c, n$ and $\eta$ are assumed constant for a given structural member, but vary randomly across members. Parameter $a$ is not independent but a function of $b$, $c, n, \eta$ and $\sigma_{\mathrm{s}}[21]$.

Stress history $\sigma(t)$ in a member can be expressed with Eq. (6). The load variables in Eq. (6) are different from those in Eq. (3). For short-term analysis the maximum load effect is concerned, therefore random variables $g$ and $q$ in Eq. (3) represent the maximum load over the design reference period. For long-term analysis, the load effect at any time $t$ should be used for damage accumulation calculation, therefore, random variables $g(t)$ and $q(t)$ in Eq. (6) represent the load history over the design reference period. The statistical load parameters for reliability evaluation of Canadian lumber can be found in the work by Foschi et al. [13]:

$$
\sigma(t)=\frac{\phi \sigma_{0.05}}{\left(\gamma_{\mathrm{G}} r+\gamma_{\mathrm{Q}}\right)}[g(t) r+q(t)] .
$$

Instead of a close-formed integration, numerical integration is used for calculation of damage index $\alpha$. The design reference period $t$ is divided into several segments of duration $\Delta t$, and the damage accumulation is calculated segment by segment from Eq. (7). In the equation, $\alpha_{i}$ is the damage index value by the end of the $i$ th time segment; $a, b, c, n$ and $\eta$ are Foschi-Yao damage model parameters; $\sigma_{i}$ is the applied stress in the $i$ th time segment calculated from Eq. (6), which is assumed constant over each time segment:

$$
\begin{aligned}
\alpha_{i} & =\alpha_{i-1} K_{i}+L_{i}, \\
K_{i} & =\exp \left[c\left(\sigma_{i}-\eta \sigma_{\mathrm{s}}\right)^{n} \Delta t\right],
\end{aligned}
$$




$$
L_{i}=\frac{a}{c}\left(\sigma_{i}-\eta \sigma_{\mathrm{s}}\right)^{b-n}\left(K_{i}-1\right) .
$$

Long-term reliability analysis for the Canada standard was performed via Monte Carlo simulations as follows: (1) relevant design conditions and parameters are prescribed. A resistance factor $\phi$, load type and ratio $r$ are selected. Statistical characteristics (the mean, COV and probability distribution) are assumed for the random variables, including load ratios $g$ and $q$, short-term wood strength $\sigma_{\mathrm{s}}$ and Foschi-Yao model parameters $b, c$, $n$ and $\eta$. (2) $N_{\mathrm{R}}$ sets of the parameters are generated by random sampling. Each set of the parameters include wood strength parameters $\left(\sigma_{s}, b, c, n\right.$ and $\left.\eta\right)$ for a member and the load ratios $\left(g_{i}, q_{i}\right)$ for each time segment over the design reference period. (3) For each set of the $N_{\mathrm{R}}$ samples, the performance function $Z$ is evaluated with Eqs. (4-7). The total number of the failed samples $(Z \leq 0)$ is counted to be $N_{\mathrm{F}}$. (4) The probability of failure corresponding to conditions prescribed in Step (1) is calculated as $P_{\mathrm{f}}=N_{\mathrm{F}} / N_{\mathrm{R}}$, and the corresponding reliability index is calculated as $\beta=\Phi^{-1}\left(1-P_{\mathrm{f}}\right)$, where $\Phi^{-1}$ is the inverse standard normal distribution function.

The relationships between reliability index $\beta$ and resistance factor $\phi$ were obtained from short-term and longterm reliability analysis, respectively, as shown in Fig. 1. Corresponding to a target reliability index $\beta_{0}$, the longterm resistance factor $\phi_{\mathrm{II}}$ is always smaller than the short-term value $\phi_{\mathrm{I}}$. DOL is then defined as the ratio of resistance factor $\phi_{\mathrm{II}}$ to $\phi_{\mathrm{I}}$, i.e., $K_{\mathrm{DOL}}=\phi_{\mathrm{II}} / \phi_{\mathrm{I}}$. Thus a value of $K_{\mathrm{DOL}}=0.8$ for load of standard-term duration in Canada standard was derived from the reliability analysis (on a 30-year basis) [13]. For loads of short-term and longterm duration, the difference in value of $K_{\mathrm{DOL}}$ so obtained is accounted for by introducing an adjustment factor $K_{\mathrm{D}}$, as listed in Table 2 . It follows that for short-term duration

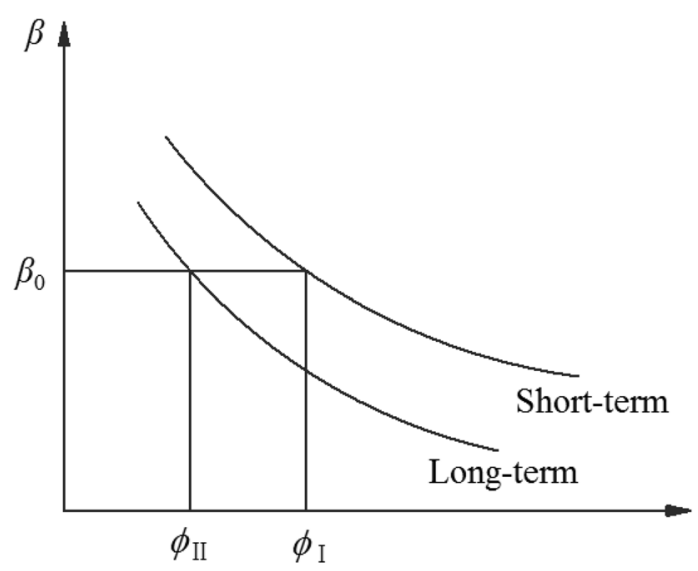

Fig. $1 \beta-\varphi$ curves from the Canada reliability analysis method
$K_{\mathrm{DOL}}=0.8 \times 1.15=0.92$, and for long-term duration $K_{\mathrm{DOL}}=0.8 \times 0.65=0.52$.

\section{Main differences in the performance functions}

The China analysis method takes account of more random variables $\left(K_{\mathrm{A}}, K_{\mathrm{P}}\right.$ and $\left.K_{\mathrm{B}}\right)$ that may affect the resistance and load effect in the performance function. These random variables, however, have limited effect on the reliability analysis results as all their mean is 1 and COV is no higher than 0.05 (see Table 1).

A more significant difference lies in the way of dealing DOL. In the performance function of China analysis method, DOL of wood is reflected by $K_{\mathrm{Q} 3}$ and $K_{\mathrm{DOL}}$, where $K_{\mathrm{DOL}}$ is a constant discounting the design strength of wood, and $K_{\mathrm{Q} 3}$ is a variable reflecting the random value of DOL. In Eq. (1), $K_{\mathrm{Q} 3}$ in the resistance term is randomly valued, with a mean being equal to the design parameter $K_{\text {DOL }}$ in the load effect term. When evaluating the reliability, mean value of $K_{\mathrm{Q} 3}$ and value of $K_{\mathrm{DOL}}$ in Eq. (1) actually offset each other, what left and really affects the reliability results is the variation of DOL. Therefore, influence of DOL on reliability analysis is actually influence of $\mathrm{COV}$ of $K_{\mathrm{Q} 3}$ ( $V_{\mathrm{KQ} 3}=0.12$ regardless of the load level and its duration over the design reference period, see Table 1). In contrast, in the Canada analysis method, reliability is directly affected by the DOL that is reflected by damage index $\alpha$. Variation of DOL is introduced by the model parameters (see Table 3 ). The COV of these model parameters is considerably high (0.075-0.574) compared to that of $K_{\mathrm{Q} 3}$ in the China analysis method.

Table 2 DOL adjustment factor $K_{\mathrm{D}}$ in CSA 086

\begin{tabular}{lll}
\hline Duration of load & $\boldsymbol{K}_{\mathbf{D}}$ & Typical load conditions \\
\hline Short-term & 1.15 & Earthquake, impact \\
Standard & 1.0 & Residential live load, snow load \\
Long-term & 0.65 & Dead load \\
\hline DOL factor $K_{\mathrm{DOL}}=0.8 K_{\mathrm{D}}$ & &
\end{tabular}

Table 3 Material parameters for western hemlock dimension lumber

\begin{tabular}{lllll}
\hline & Parameters & Mean & COV & Distribution \\
\hline Bending strength & $\sigma_{s 1}$ & $47.83 \mathrm{MPa}$ & 0.410 & Lognormal \\
Compressive strength & $\sigma_{s 2}$ & $34.12 \mathrm{MPa}$ & 0.246 & Lognormal \\
Foschi-Yao damage & $b$ & 37.161 & 0.281 & Lognormal \\
model parameters & $c$ & $1.623 \times 10^{-4}$ & 0.574 & Lognormal \\
& $n$ & 1.290 & 0.075 & Lognormal \\
& $\eta$ & 0.533 & 0.298 & Lognormal \\
\hline
\end{tabular}




\section{Material and load parameters in reliability analysis}

For assessing the relative safety level achieved from the China and Canada reliability analysis methods, the input parameters for wood and load profiles are carefully chosen such that they are as closely comparable as possible.

\section{Material parameters}

Western Hemlock dimension lumber is used to conduct the reliability analyses. To explore the influence of different variations of strength, members under bending and members under compression are included in the study. Specifically, the bending strength of lumber $\left(2^{\prime \prime} \times 6^{\prime \prime}\right.$, No. 2 and better) [13] and the compression strength of lumber $\left(2^{\prime \prime} \times 4^{\prime \prime}\right.$, No. 2) [22] are used, as listed in Table 3 . The COV of strength is 0.410 for bending and 0.246 for compression, respectively. The lumber strength is assumed to follow a lognormal probability distribution, and the relationship in Eq. (2) applies. In the analysis the characteristic strength $f_{\mathrm{k}}$ in the China method is equivalent to the nominal strength $\sigma_{0.05}$ in the Canada method.

The estimated Foschi-Yao model parameters [13] are adopted in the current analysis, e.g., mean $(b)=37.161$, COV $(b)=0.281$ (see Table 3 ). It is noted that uncertainties of parameter estimates for damage accumulation models do exist, viz. different estimates of the model parameters might be obtained if model fitting were carried out for different materials, different samples of the same material, or even the same material sample employing different fitting methods. Influence of such uncertainties was initially examined by Foschi et al. [13] and more recently Chun-Hao Yang et al. [23] proposed a Bayesian framework for model fitting with better likelihood. The uncertainties of model parameter estimates are a rather complicated problem beyond the scope of this study.

\section{Load parameters}

Statistical data from the China load code GB 50009 [24] are adopted to derive the load parameters for reliability analysis, as tabulated in Tables 4, 5, 6. The design reference period is 50 years. For the China analysis method, the statistical characteristics of load are listed in Table 4.

For the Canada analysis method, the damage accumulation model requires division of the design reference period into proper number of segments as well as determination of load ratio $g$ and $q$ over each segment. The load statistical parameters are listed in Table 5. Loads at different points of time are randomly sampled according to the statistical characteristics. Specifically, for a given member, the value of dead load is sampled only once, and is assumed to last all through the whole design reference period. Floor live load is superposition of a sustained part and an extraordinary part, both alter once every 10 years, and therefore, one random sampling is made for every
Table 4 Statistical parameters of loads for the China analysis method

\begin{tabular}{llll}
\hline Load type & Mean & COV & Probability distribution \\
\hline 9 & 1.06 & 0.070 & Normal \\
\multicolumn{1}{c}{ Dead load } & & & \\
9 & 0.524 & 0.288 & Extreme Type I \\
Live load (office floor) & 0.644 & 0.233 & Extreme Type I \\
$\begin{array}{llll}\text { Live load (residential floor) } \\
\text { Snow (50-year return period) }\end{array}$ & 1.04 & 0.220 & Extreme Type I \\
\hline
\end{tabular}

Characteristic live load (office or residential) $=2.0 \mathrm{kN} / \mathrm{m}^{2}$

10-year period. The sustained part of floor live load is assumed to last over the whole period, while the extraordinary floor live load is assumed to be intermittent, lasting $4 \mathrm{~h}$ per week [25].

Reference snow load specified in load code GB 50009 [24] is derived on the basis of statistical data of annual maximum snow pressure $S_{0}$, which is a random variable following an Extreme Type I probability distribution. The cumulative probability distribution of $S_{0}$ is expressed in Eq. (8), and the maximum snow pressure $S_{0, R}$ of return period $R$ is expressed in Eq. (9):

$$
\begin{aligned}
& F(x)=\exp \{-\exp [-\alpha(x-u)]\}, \\
& S_{0, R}=u-\frac{1}{\alpha} \ln \left[\ln \left(\frac{R}{R-1}\right)\right],
\end{aligned}
$$

where $u$ and $\alpha$ are probability distribution parameters; $R$ is the return period, in years. $S_{0,10}, S_{0,50}$ and $S_{0,100}$ for some cities in China are tabulated in load code GB 50009 [24], from which the parameters $u$ and $\alpha$ can be backcalculated via Eq. (9). For example, the snow statistical parameters for Beijing are listed in Table 6. $S_{0,50}$ is taken as the reference snow pressure for a 50-year design reference period, and the nominal snow pressure on roof is calculated as $\mu_{\mathrm{r}} S_{0,50}$, where $\mu_{\mathrm{r}}$ is a snow distribution factor dependent on roof shape, wind direction and velocity.

For the China reliability analysis method, the maximum snow load (over a 50-year design reference period) is used, the statistical parameters of which are included in Table 4.

For the Canada reliability analysis method, the snow pressure history (instead of the maximum pressure) within the design reference period is needed for calculation of damage accumulation. The snow load history is derived from the annual maximum snow pressure $S_{0}$ referring to research by Foschi et al. [13]. Assume that winter is 5-month-long each year and it is divided into $N$ segments, each of duration $\Delta t$. Snow pressure in each segment $\Delta t$ is assumed to remain constant. The cumulative probability distribution of snow pressure in each 
Table 5 Statistical parameters of live load for the Canada analysis method

\begin{tabular}{llllll}
\hline Load type & $\begin{array}{l}\text { Alteration period/ } \\
\text { year }\end{array}$ & Duration of load & $\begin{array}{l}\text { Mean value/nominal } \\
\text { value }\end{array}$ & COV & Probability distribution \\
\hline $\begin{array}{l}\text { Dead load } \\
\text { Office floor live load }\end{array}$ & - & 50 years & 1.06 & 0.070 & Normal \\
$\begin{array}{l}\text { Sustained } \\
\begin{array}{l}\text { Extraordinary } \\
\text { Residential floor live load }\end{array}\end{array}$ & 10 & 50 years & 0.193 & 0.461 & Extreme Type I \\
$\begin{array}{l}\text { Sustained } \\
\text { Extraordinary }\end{array}$ & 10 & 4 h/week & 0.178 & 0.687 & Extreme Type I \\
\hline
\end{tabular}

Nominal live load (office or residential) $=2.0 \mathrm{kN} / \mathrm{m}^{2}$

Table 6 Some reference snow pressure and probability distribution parameters for Beijing

\begin{tabular}{lllll}
\hline $\boldsymbol{S}_{\mathbf{0 , 1 0}} / \mathbf{k P a}$ & $\boldsymbol{S}_{\mathbf{0 , 5 0}} / \mathbf{k P a}$ & $\boldsymbol{S}_{\mathbf{0 , 1 0 0}} / \mathbf{k P a}$ & $\boldsymbol{U}$ & $\boldsymbol{a}$ \\
\hline 0.25 & 0.4 & 0.45 & 0.05846 & 11.74891 \\
\hline
\end{tabular}

segment is assumed the same but mutually independent, which is denoted $F_{\mathrm{S}}(x)$. The cumulative probability distribution of annual maximum snow pressure is denoted $F(x)$ (see Eq. (8)). It's evident that the probability distribution of the maximum value among the $N$ segments should equal the probability distribution of the annual maximum snow pressure. Assume that $p_{\mathrm{s} 0}$ and $p_{0}$ are, respectively, the probability of not snowing in a segment $\Delta t$ and in a year $(N \cdot \Delta t)$, the expressions in Eqs. $(10,11)$ stand. The cumulative distribution function $F_{\mathrm{S}}(x)$ can be derived as Eq. (12):

$$
\begin{aligned}
& F(x)=\left[p_{\mathrm{S} 0}+\left(1-p_{\mathrm{S} 0}\right) F_{\mathrm{S}}(x)\right]^{N}, \\
& p_{\mathrm{S} 0}{ }^{N}=p_{0}=\exp [-\exp (\alpha u)], \\
& x=u-\frac{1}{\alpha} \ln \left\{-N \ln \left[p_{\mathrm{S} 0}+\left(1-p_{\mathrm{S} 0}\right) F_{\mathrm{S}}(x)\right]\right\} .
\end{aligned}
$$

For Monte Carlo simulations in the Canada analysis method, the snow load $S_{\Delta t}=x$ in a time segment can be sampled with Eq. (12) by assigning a random number (uniformly distributed between 0 and 1) to $F_{\mathrm{s}}(x)$. Load ratio $q(t)$ for use in Eq. (6) is determined as

$$
q(t)=\frac{\mu_{\mathrm{r}} S_{\Delta t}}{\mu_{\mathrm{r}} S_{0,50}}=\frac{S_{\Delta t}}{S_{0,50}} .
$$

\section{Load combinations}

Four load combinations are considered, these include dead load alone and three other combinations of dead load and a single live load, i.e., office floor live, residential floor live and snow load. For each combination involving a live load, the ratio of nominal live load to nominal dead load [ $\rho$ in Eq. (1) or $1 / r$ in Eq. (5)] is assigned a series of values, as $0.25,0.5,1.0,2.0,3.0$ and 4.0 , respectively.

The load partial factors specified in load code GB 50009 [24] are used. For the case of dead load alone, the load partial factor $\gamma_{\mathrm{G}}=1.35$; for the combinations of dead load and a single live load, the dead load partial factor $\gamma_{\mathrm{G}}=1.2$, the live load partial factor $\gamma_{\mathrm{Q}}=1.4$, and the combination factor $\psi_{\mathrm{c}}=1.0$.

\section{Unified format of result presentation}

The China analysis method introduces DOL explicitly with a factor $K_{\mathrm{DOL}}$ (see "The China reliability analysis method" section), while the Canada analysis method has the DOL factor implicitly included in the resistance factor $\phi$ (see "The Canada reliability analysis method" section, $\phi_{\mathrm{II}}=\phi_{\mathrm{I}} K_{\mathrm{DOL}}$ ). Term $\gamma_{\mathrm{R}} / K_{\mathrm{DOL}}$ in the China analysis method is thus equivalent to term $1 / \phi$ in the Canada analysis method. To enable comparison between the reliability analysis results, a unified resistance partial factor $\gamma_{\mathrm{R}}{ }^{*}$ is defined and used in place of the two equivalent terms, i.e., $\gamma_{R}^{*}=1 / \phi$ for the Canada analysis method, and $\gamma_{\mathrm{R}}{ }^{*}=\gamma_{\mathrm{R}} / K_{\mathrm{DOL}}$ for the China analysis method.

\section{Results and discussion}

Reliability analysis of hemlock dimension lumber under bending and under compression was conducted using the China analysis method and the Canada analysis method, respectively. The results are discussed as follows. Note that only long-term analysis was carried out for the Canada analysis method, the results from which are comparable to those from the China analysis method.

\section{Dead load alone}

The $\beta-\gamma_{R}^{*}$ curves for the case of dead load alone are plotted in Fig. 2. It is observed that the China curves lie above the corresponding Canada curves. Given the same reliability index $\beta$, the resistance partial factor $\gamma_{\mathrm{R}}{ }^{*}$ resulted 
from the China reliability analysis method is smaller than that from the Canada analysis method. This means that for dead load alone, the China analysis method results in less conservative design than the Canada analysis method. Specifically, at a reliability index of 3.2, the target reliability index by the China code requirement [26], the $\gamma_{R}{ }^{*}$ value for bending by the China analysis method and the Canada analysis method is 2.63 and 3.19, respectively, resulting in a ratio of about 0.82 . This higher conservatism of the Canada analysis method is due to the damage accumulation model it assumes.

The variations of DOL model parameters are high in the Canada analysis method, as described in "Main differences in the performance functions" section, this leads to severer DOL, hence the higher conservatism. E. g., for dead load alone, the DOL factor in the China wood standard GB 50005 [19] is 0.576 for 50 -year duration ("The China reliability analysis method" section), while that in the Canada standard CSA O86 [20] is 0.52 for 30-year duration ("The Canada reliability analysis method" section), as calculated by the Canada reliability analysis. Although variables $K_{\mathrm{A}}, K_{\mathrm{P}}$ and $K_{\mathrm{B}}$ introduce extra variations in the China analysis method, they are overweighed by the smaller DOL value in the Canada analysis method, and the China method still results less conservative design.

\section{Dead load combined with a live load}

The results for combination of dead and residential floor live load are similar to that for combination of dead and office floor live load, the results for the latter combination are demonstrated in Figs. 3 and 4. Comparison of the $\beta-\gamma_{\mathrm{R}}{ }^{*}$ curves at load ratios of $\rho=0.25,1.0,2.0$ and

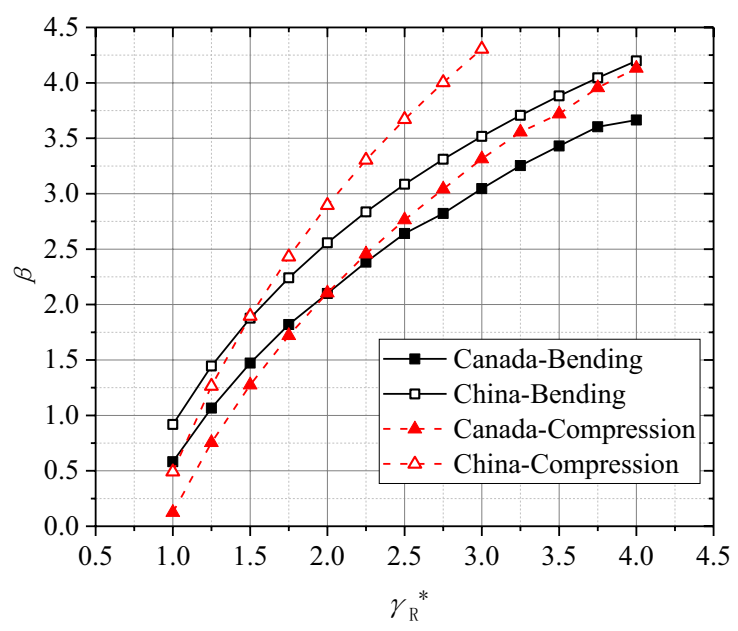

Fig. 2 Reliability results of western hemlock dimension lumber under dead load alone
4.0 is shown in Fig. 3. It is observed that at a lower ratio of $\rho=0.25$, the China curves lie considerably higher, i.e., less conservative, than the corresponding Canada curves. As load ratio $\rho$ increases, the Canada curves gradually approach (when $\rho \leq 2.0$ ) and finally go slightly higher than $(\rho=4.0)$ the China curves. Influence of load ratio $\rho$ on the $\beta-\gamma_{\mathrm{R}}{ }^{*}$ curves is shown in Fig. 4. The four clusters of curves all demonstrate a growing trend of $\beta$ with load ratio $\rho$. The growth rate gradually decreases, and the curves in each cluster asymptotically approach a final location. The change with respect to load ratio $\rho$ between the Canada curves is more significant than that between the China curves, indicating a higher sensitivity to load ratio $\rho$.

For combination of dead and snow load, snow load characteristics of Beijing are used as an example. The $\beta-$ $\gamma_{R}{ }^{*}$ curves for this load combination are shown in Figs. 5 and 6. As reflected in Fig. 5, at a lower ratio of $\rho=0.25$, the China curves still lie higher, i.e., less conservative, than the Canada curves, but the Canada curves overtake quickly when load ratio $\rho$ increases and the Canada curves remains a bit higher than China curves when $\rho \geq 2.0$. It can be seen from Fig. 6 that for this load combination, the change of the $\beta-\gamma_{\mathrm{R}}{ }^{*}$ curves with respect to load ratio $\rho$ is obviously less significant than combination of dead and office floor live load as described above. The clusters of the China curves in Fig. 6a, c demonstrate hardly any change with load ratio $\rho$, and the change of the Canada curves in Fig. 6b, d is also minor compared to the counterparts in Fig. 4.

In general, for combinations of dead load and a single live load, the Canada analysis method gives not as conservative results as it does for the case of dead load alone. When load ratio $\rho$ increases, i.e., when live load makes up an increasing portion of the total load, the Foschi-Yao model in the Canada analysis method captures the changes in stress level and duration of load, resulting in increasingly alleviated DOL. Contrarily, DOL is not altered in the China analysis method in this process. This results in a higher sensitivity of the Canada analysis method to load ratio $\rho$ in comparison with the China analysis method.

It's further observed that differences in the analysis results are not only made by the load ratio $\rho$ but also by the specific type of live load. The mechanism how characteristics of the load effect term affect the reliability index values is further discussed in "Influence from characteristics of the load effect term" section.

\section{Influence from characteristics of the load effect term}

As can be seen from the analysis above, the load effect term (more specifically the load ratio $\rho$ as well as the load type) is of significant influence on the relative safety level 


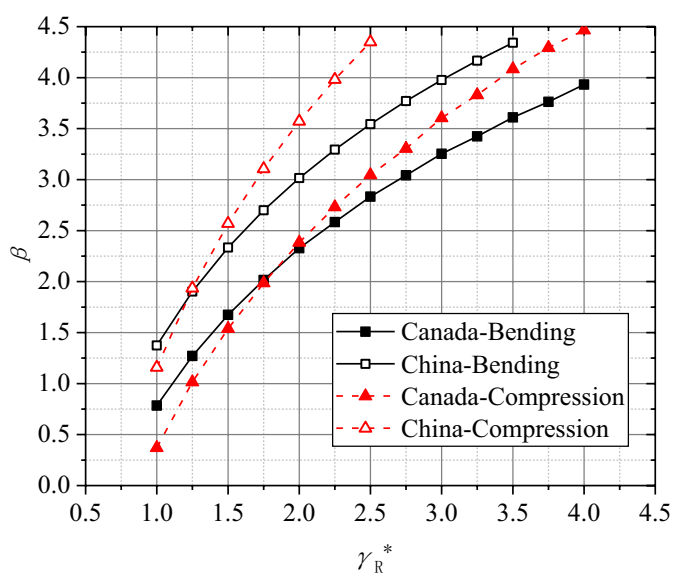

a $\rho=0.25$

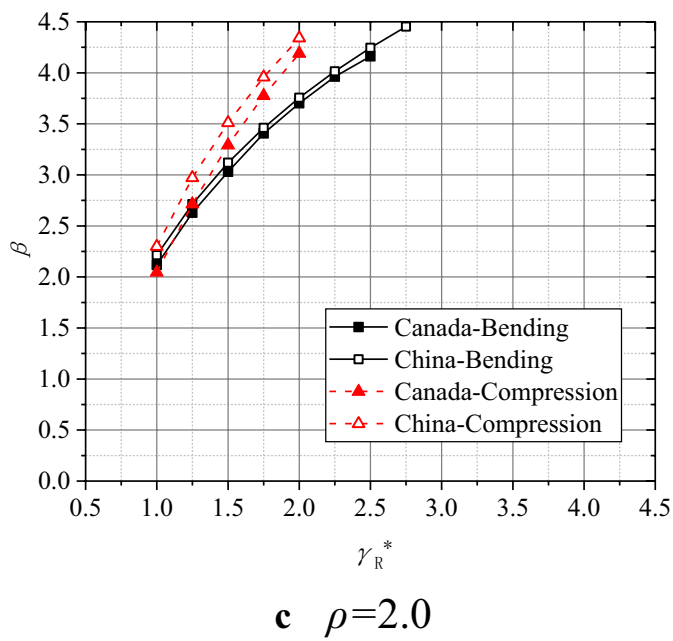

Fig. 3 Reliability results for combination of dead and office floor live load

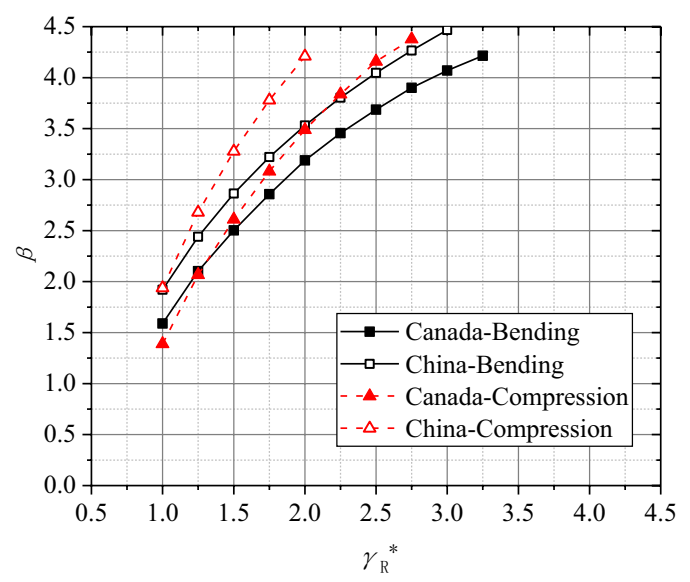

b $\rho=1.0$

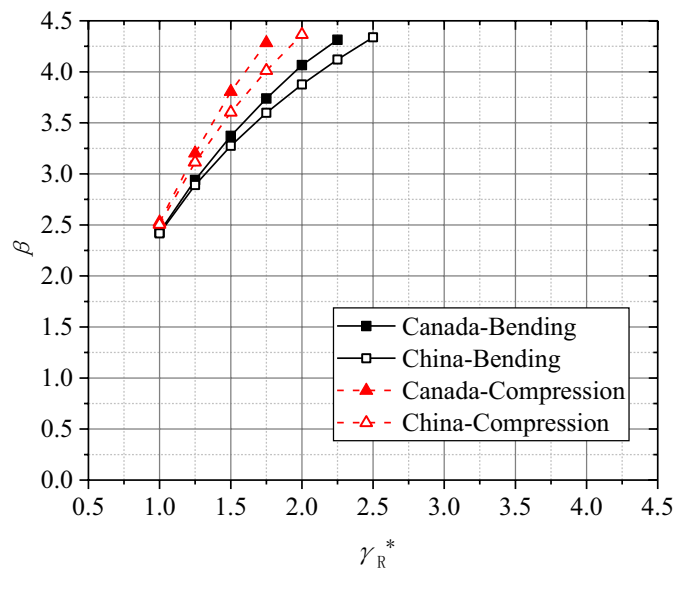

d $\rho=4.0$ between the China and the Canada analysis methods. Influence from statistical characteristics of the load effect term on reliability index is investigated as follows.

In addition to the unified resistance partial factor $\gamma_{\mathrm{R}}{ }^{*}$, the load effect term in the Canada and the China analysis methods is mainly dependent on items $[g(t) r+q(t)] /$ $\left(\gamma_{\mathrm{G}} r+\gamma_{\mathrm{Q}}\right)$ and $(g+q \rho) /\left(\gamma_{\mathrm{G}+} \gamma_{\mathrm{Q}} \rho\right)$, respectively (see Eqs. (1) and (6)). Note that little difference is made by variable $K_{\mathrm{B}}($ mean $=1.0, \mathrm{COV}=0.05)$ in the China load effect term. Item $(g+q \rho) /\left(\gamma_{\mathrm{G}+} \gamma_{\mathrm{Q}} \rho\right)$ in the China analysis method is analyzed here as an example, its mean and $\mathrm{COV}$ are expressed, respectively, as

$$
\left(\frac{g+q \rho}{\gamma_{\mathrm{G}}+\gamma_{\mathrm{Q}} \rho}\right)_{\mathrm{m}}=\frac{g_{\mathrm{m}}+q_{\mathrm{m}} \rho}{\gamma_{\mathrm{G}}+\gamma_{\mathrm{Q}} \rho}
$$

$$
V_{\left(\frac{g+q \rho}{\gamma_{\mathrm{G}}+\gamma_{\mathrm{Q}} \rho}\right)}=\frac{\sqrt{V_{\mathrm{g}}^{2} g_{\mathrm{m}}^{2}+\rho^{2} V_{\mathrm{q}}^{2} q_{\mathrm{m}}^{2}}}{g_{\mathrm{m}}+\rho q_{\mathrm{m}}},
$$

where $(X)_{\mathrm{m}}$ and $V_{(\mathrm{X})}$ denote the mean and COV of a random variable $X$, respectively.

As load ratio $\rho$ increases, the mean of item $(g+q \rho) /$ $\left(\gamma_{\mathrm{G}+} \gamma_{\mathrm{Q}} \rho\right)$ should start from $g_{\mathrm{m}} / \gamma_{\mathrm{G}}$ (when $\rho=0$ ) and asymptotically approach a final value of $q_{\mathrm{m} /} / \gamma_{\mathrm{Q}}$ (when $\rho \rightarrow \infty)$. If $g_{\mathrm{m}} / \gamma_{\mathrm{G}}=q_{\mathrm{m} /} / \gamma_{\mathrm{Q}}$, no change is incurred by change of $\rho$, for this case a critical value of $q_{\mathrm{m}}$ can be identified as $q_{\mathrm{m}, \mathrm{cr}}=g_{\mathrm{m}} \gamma_{\mathrm{Q}} / \gamma_{\mathrm{G}}$. In a similar way, the COV of item $(g+q \rho) /\left(\gamma_{\mathrm{G}+} \gamma_{\mathrm{Q}} \rho\right)$ changes from $V_{\mathrm{g}}($ when $\rho=0)$ to a final value of $V_{\mathrm{q}}$ (when $\rho \rightarrow \infty$ ). Note that the mean of item $(g+q \rho) /\left(\gamma_{\mathrm{G}+} \gamma_{\mathrm{Q}} \rho\right)$ is affected to some extent by the $\gamma_{\mathrm{G}}$ and $\gamma_{\mathrm{Q}}$ values, while the COV of it is not affected. 


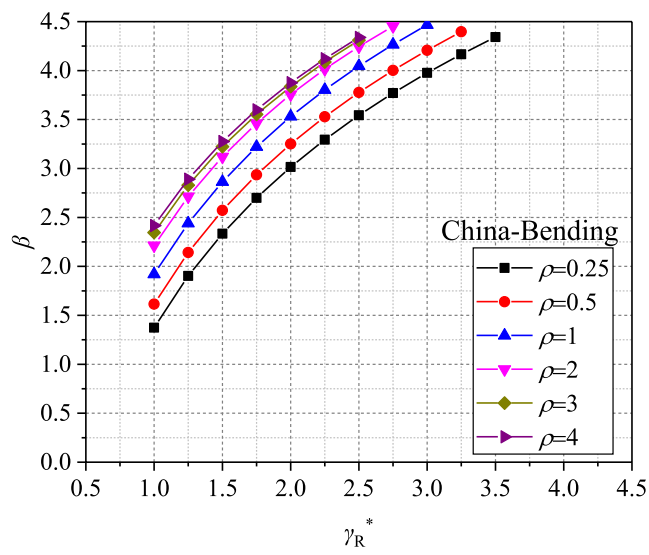

a China-Bending

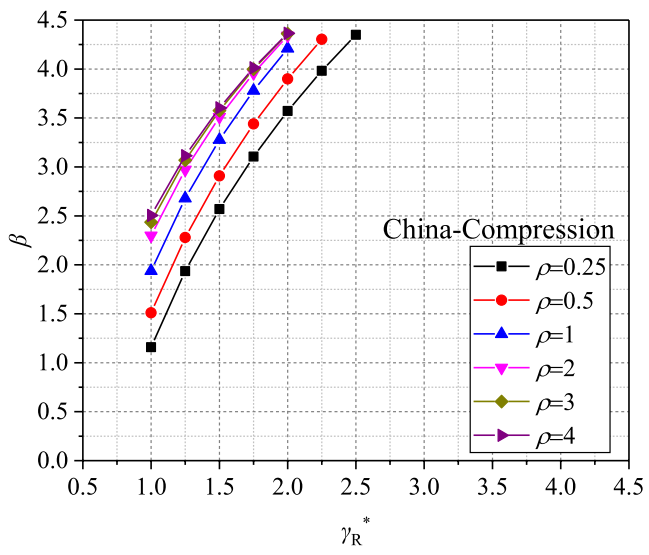

c China-Compression

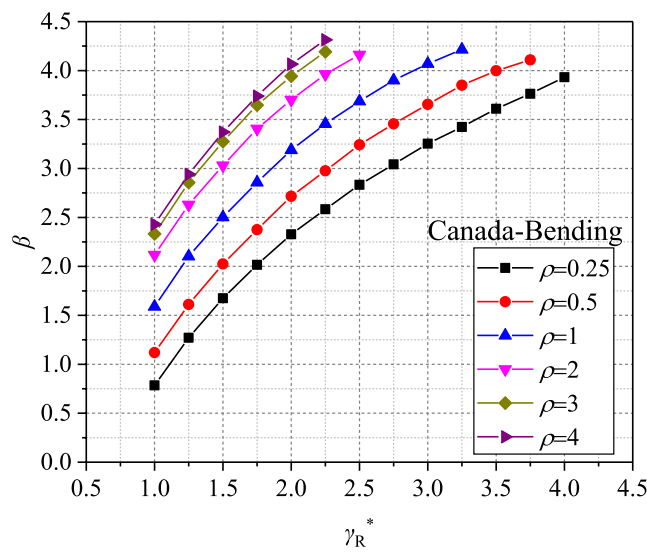

b Canada-Bending

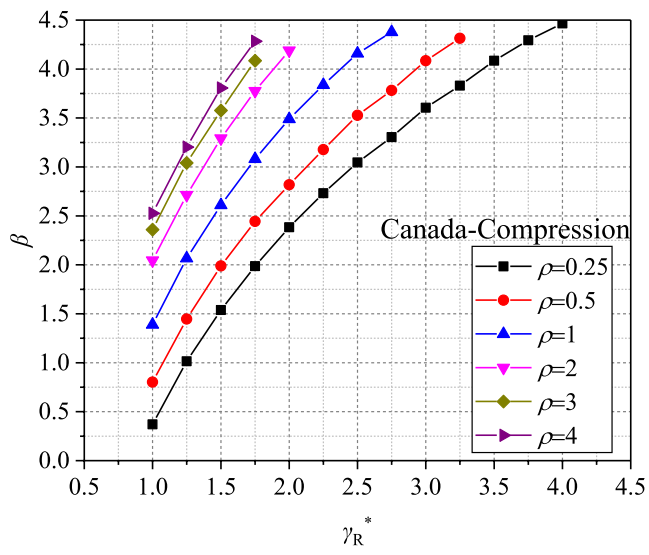

d Canada-Compression

Fig. 4 Influence of load ratio $\rho$ for combination of dead and office floor live load

Assuming $\gamma_{\mathrm{G}}=1.2$ and $\gamma_{\mathrm{Q}}=1.4$, and taking the statistical parameters of $g$ and $q$ from Table 4, the trend lines of mean and COV of item $(g+q \rho) /\left(\gamma_{\mathrm{G}+} \gamma_{\mathrm{Q}} \rho\right)$ with $\rho$ are plotted in Fig. 7a, b. It's observed that the change rate of mean and COV of load effect is large when $\rho$ is small, and the rate diminishes gradually as $\rho$ goes higher. Among the three live loads, snow load is of a mean load ratio $\left(q_{\mathrm{m}}=1.04\right.$, see Table 4$)$ closest to the critical value $\left(q_{\mathrm{m}, \mathrm{cr}}=g_{\mathrm{m}} \gamma_{\mathrm{Q}} / \gamma_{\mathrm{G}}=1.06 \times 1.4 / 1.2=1.24\right)$, therefore, it triggers a minimum extent of change in the mean load effect as shown in Fig. 7a. A change in the load partial factors, for example, to $\gamma_{\mathrm{G}}=1.25$ and $\gamma_{\mathrm{Q}}=1.5$ as specified in the Canada standard, makes minor difference which is not altering the general trend of curves in Fig. 7a.

Moreover, for the cases of residential or office floor live load, the beneficial decrease of mean value would overweigh the detrimental increase of COV of the load effect term. As a result, the reliability index resulted from the China analysis method increases with load ratio $\rho$ for these two load combinations, see Fig. 4a, c. The variation rate of the $\beta-\gamma_{\mathrm{R}}{ }^{*}$ curves with load ratio $\rho$ is gradually diminishing, which matches the trend of variation in Fig. 7. For combination of snow load, the beneficial decrease of the mean would approximately counterbalance the detrimental increase of COV of the load effect term. Therefore, the $\beta-\gamma_{\mathrm{R}}{ }^{*}$ curves vary little between different load ratios $\rho$, see Fig. 6a, c.

Similar trends exist in item $[g(t) r+q(t)] /\left(\gamma_{\mathrm{G}} r+\gamma_{\mathrm{Q}}\right)$ of load effect term in the Canada analysis method, except for that variables $g(t)$ and $q(t)$ have some different statistical parameters as listed in Table 5 . The beneficial decrease in the mean value of load effect is more significant than that for the China analysis method.

\section{Influence from COV of material strength}

In the current analysis, two variation levels of dimension lumber strength are included, viz. $\mathrm{COV}=0.410$ for bending strength and $\mathrm{COV}=0.246$ for compression strength of lumber (Table 3). It's straightforward that as COV of 


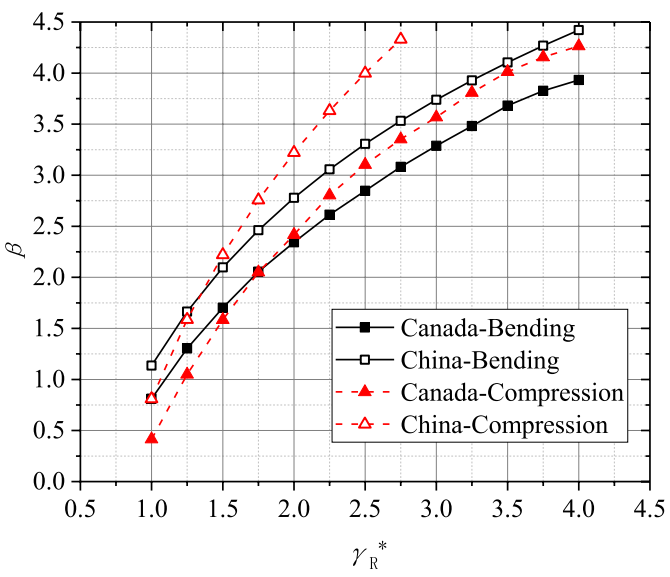

a $\rho=0.25$

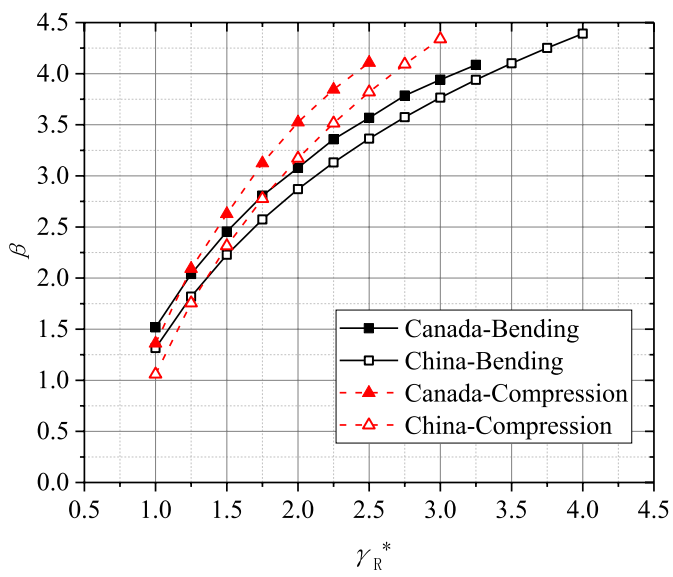

c $\rho=2.0$

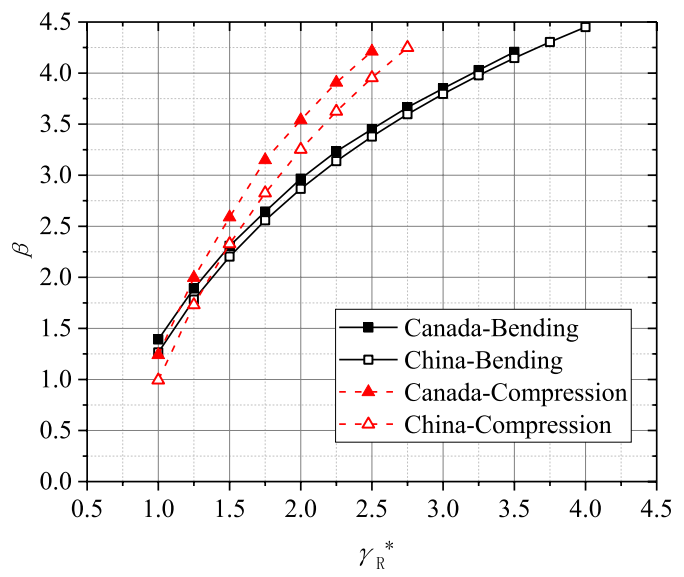

b $\rho=1.0$

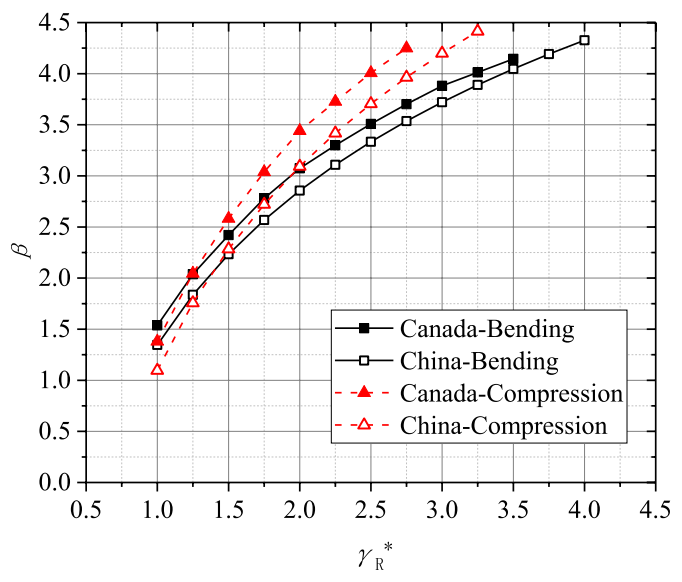

d $\rho=4.0$

Fig. 5 Reliability results for combination of dead and snow load (Beijing)

lumber strength decreases, the reliability index $\beta$ tends to increase in both analysis methods, as reflected in Figs. 2, $3,4,5$, and 6 . However, COV level of lumber strength is not found to make significant difference in the safety level comparison between the two analysis methods, as reflected by comparison between the 'bending' and 'compression' results in Figs. 2, 3 and 5.

\section{Conclusions}

The reliability analysis methods underlying China and Canada standards for wood structures are investigated, with special attention paid to the way how DOL is treated. To compare the safety level achieved by the two methods, reliability analysis was carried out on the basis of the same set of material properties and load parameters. Examples in this study reflect that the influence on structural safety of the China and the Canada analysis methods varies from case to case, depending on the variation level of variables in their performance functions. If the same reliability level were given, the Canada analysis method would tend to result in more conservative design than the China analysis method for dead load-dominated cases. This is a result of more significant influence from DOL in the Canada analysis method for this loading condition, which considerably overweighs the influence of extra random variables $\left(K_{\mathrm{A}}, K_{\mathrm{P}}\right.$ and $\left.K_{\mathrm{B}}\right)$ in the China analysis method. As live loads make up an increasing portion of the total load, DOL resulted from the Canada analysis method is considerably alleviated while DOL in the China analysis method is virtually not affected. Therefore, the Canada analysis method results in not as conservative design as it does in the dead load-dominated case. In 


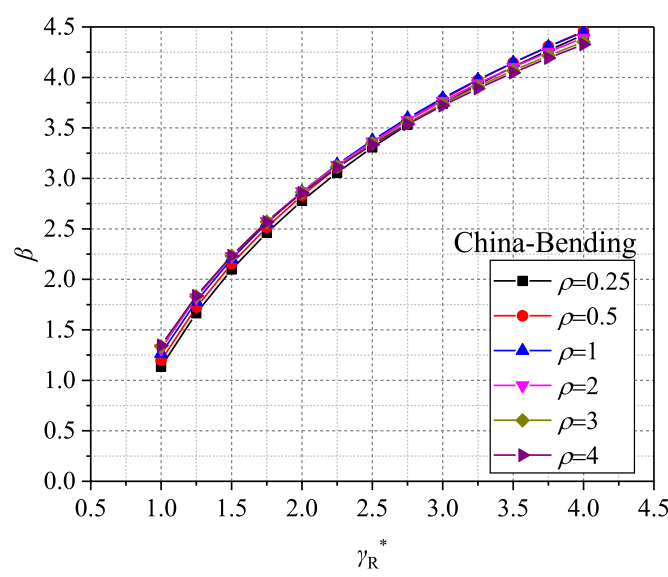

a China-Bending

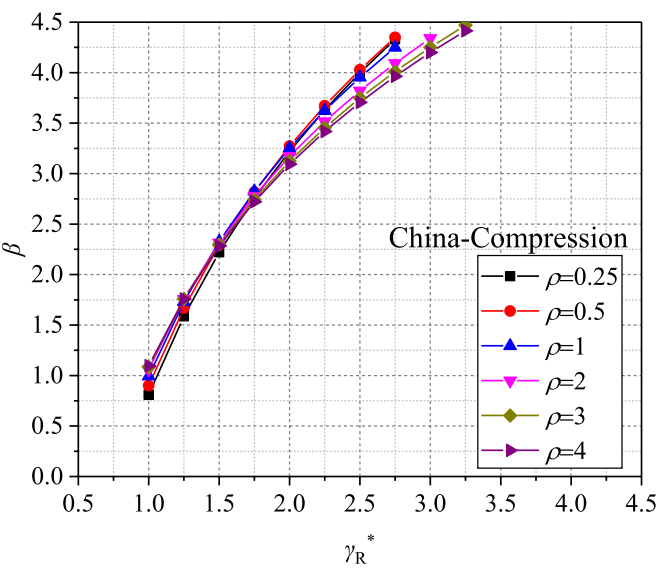

c China-Compression

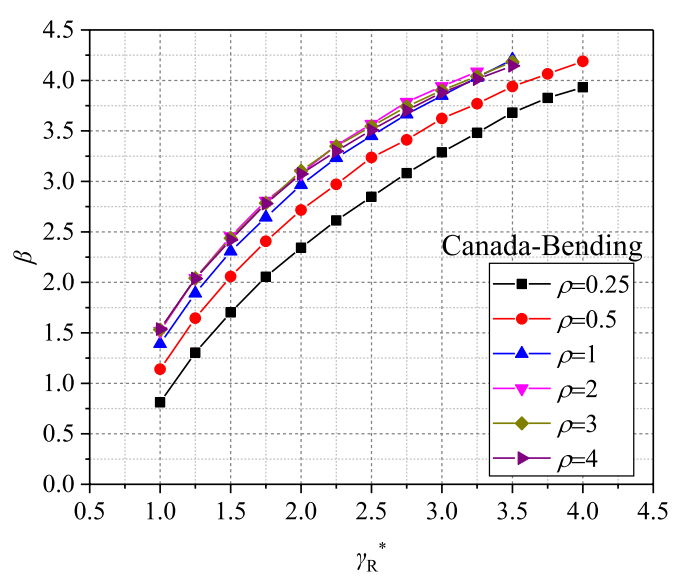

b Canada-Bending

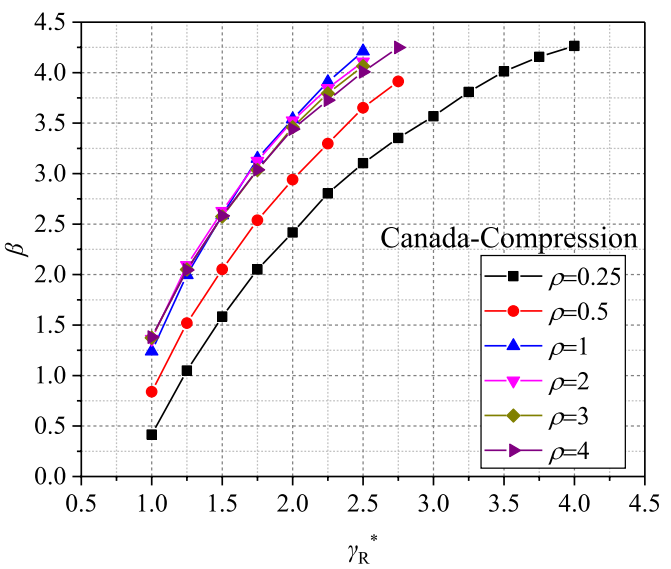

d Canada-Compression

Fig. 6 Influence of load ratio $\rho$ for combination of dead and snow load (Beijing)

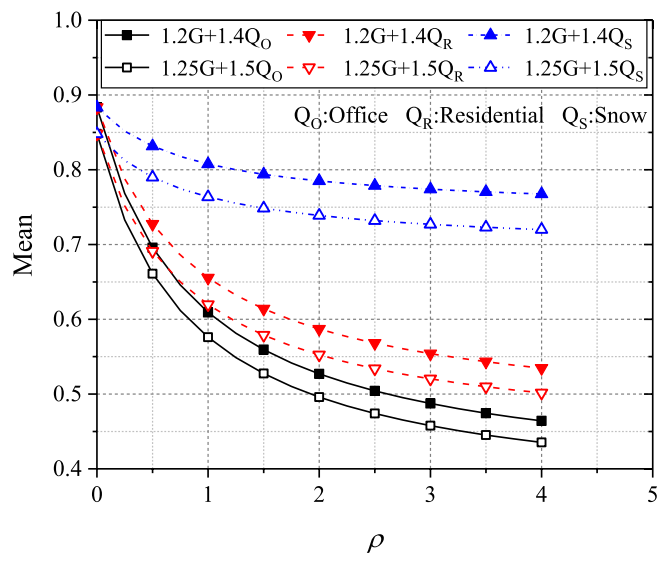

a Mean of $(g+q \rho) /\left(\gamma_{\mathrm{G}}+\gamma_{\mathrm{Q}} \rho\right)$

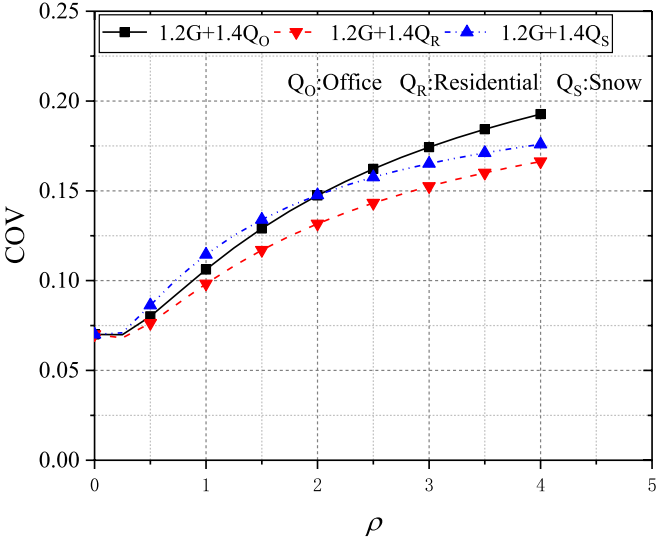

b COV of $(g+q \rho) /\left(\gamma_{\mathrm{G}}+\gamma_{\mathrm{Q}} \rho\right)$

Fig. 7 Trend lines of the load effect term in the China analysis method 
some cases with high portion of live loads, Canada analysis method can result in slightly unconservative design in comparison with the China analysis method.

In a more general sense, though target reliability index $\beta$ is an important measure for controlling and unifying the level of risk in construction engineering in a country/ region, it should be carefully used for comparison when different reliability analysis methods are involved (which is typically the case when international design codes are evaluated). Safety level is not only dependent on the target reliability index $\beta$ adopted by a design standard, but also related to the assumptions and treatments of variables or parameters and specific analysis method employed. Safety level of wood structure design is significantly affected by the inclusion of different random variables, and more importantly, different DOL models in the reliability analysis.

Finally, we would like to conclude that, this study is not to address the real reliability issues in either the China wood standard GB 50005 or the Canada wood standard CSA O86, but to make comparisons of the influence on the safety issues by different reliability analysis methods employing different assumptions and different treatments of some variables. Understanding of the similarities and differences between national wood standards would help enhance international exchanges and collaborations in wood industry.

\section{Abbreviations}

DOL: Duration of load; COV: Coefficient of variation.

\section{Acknowledgements}

The authors acknowledge the advice and help offered by postgraduate student Mr. Jin Yibo in Harbin Institute of Technology.

\section{Authors' contributions}

NS: interpretation of results, original drafting, revising and editing. WQ: calculation, original drafting, revising and editing. ZE: conceptualization, revising and validation. All authors read and approved the final manuscript.

\section{Funding}

This work was supported by National Natural Science Foundation of China Grant Number 51778187.

\section{Availability of data and materials}

The datasets used and analyzed during the current study are available from the corresponding author on reasonable request.

\section{Competing interests}

The author declares that they have no competing interests.

\section{Author details}

${ }^{1}$ School of Civil Engineering, Key Lab of Structures Dynamic Behavior and Control of China Ministry of Education, Harbin Institute of Technology, Harbin 150090, China. ${ }^{2}$ Department of Civil Engineering, Harbin Institute of Technology at Weihai, Weihai 264209, China.

Received: 28 April 2020 Accepted: 1 October 2020

Published online: 20 October 2020

\section{References}

1. ISO 2394 (2015) General principles on reliability for structures. International Organization for Standardization, Geneva, Switzerland

2. Karacabeyli E, Soltis LA (1991) State-of-the-art report on duration of load research for lumber in North America. In: Proceedings of the 1991 international timber engineering conference, London, UK, 4: 4.141-144.155

3. Buffon GL, Le Clerc, Compte de (1740) Experiences sur la Force du Bois, Paris L'Academic Royale des Sciences, Histoire et Memoires, 453-467

4. Liang T (1973) On the statistical parameters for wood member capacity. Research report, research group for reliability of wood structures, Chengdu, China (in Chinese)

5. Foschi R, Barrett JD (1982) Load-duration effects in western hemlock lumber. J Struct Eng ASCE 108(7):1494-1510

6. Hoffmeyer P, Sørensen JD (2007) Duration of load revisited. Wood Sci Technol 41(8):687-711

7. Ranta-Maunus A (2007) Strength of Finnish grown timber. VTT Publications, Espoo, pp 1-63

8. Wood LW (1951) Relation of strength of wood to duration of load Madison, Forest Products Lab, US Dept of Agriculture, Forest Service, Rep R1916

9. Gerhards CC (1979) Time-related effects on wood strength: a linear cumulative damage theory. Wood Sci 11:139-144

10. Barrett JD (2011) Foschi RO (1978) Duration of load and probability of failure in wood. Part II. Constant, ramp, and cyclic loadings. Can J Civil Eng 5(4):515-532

11. Foschi RO, Yao FZ (1986) Another look at the three duration of load models. In: Proceedings of IUFRO Wood Engineering Group meeting, Florence, Italy

12. Wong SWK, Zidek JV (2019) The duration of load effect in lumber as stochastic degradation. IEEE Trans Reliab 68(2):410-419

13. Foschi RO, Folz BR, Yao FZ (1989) Reliability-based design of wood struc tures. Structural Research Series Report No. 34, Dept. of Civil Engineering, University of British Columbia, Vancouver, Canada

14. Zhu EC, Niu S, Qiao L, Pan JL (2017) Reliability analysis of wood structures and method for determining design strength value of timber. J Build Struct 38(2):28-36 (in Chinese)

15. Ellingwood B, Rosowsky D (1991) Duration of load effects in LRFD for wood construction. J Struct Eng ASCE 117(2):584-599

16. Ranta-Maunus A, Fonselius $\mathrm{M}$ et al (2001) Reliability analysis of timber structures. VTT Publications, Espoo, pp 3-102

17. Zmijewki T, Wojtowicz-Jankowska D (2017) Timber-material of the future-examples of small wooden architectural structures. In: World Multidisciplinary Civil Engineering-Architecture-Urban Planning Symposium 2017, Prague, Czech republic, Institute of Physics Publishing

18. Brandner R, Flatscher $\mathrm{G}$ et al (2016) Cross laminated timber (CLT): overview and development. Eur J Wood Wood Prod 74(3):331-351

19. GB 50005-2017 (2018) Standard for design of timber structures. China Architecture \& Building Industry Press, Beijing, China (in Chinese)

20. CSA O86-14 (2014) Engineering design in wood. Canadian Standard Association, Mississauga, Ontario, Canada

21. Foschi RO, Yao FZ (1986) Duration of load effect and reliability based design (single member). In: Proceedings of IUFRO Wood Engineering Group Meeting, Florence, Italy

22. Barrett JD, Lau W (1994) Canadian lumber properties. Canadian Wood Council, Ottawa. ISBN: 0-921628-28-5

23. Yang CH, Zidek JV, Wong SW (2019) Bayesian analysis of accumulated damage models in lumber reliability. Technometrics 61(2):233-245

24. GB 50009-2012 (2012) Load code for the design of building structures. China Architecture \& Building Press, Beijing, China (in Chinese)

25. Wu XQ, Yao J, Liu Y (2012) Statistical analysis of live load on residence floor and analysis of residence floor reliability. Eng Mech 29(3):90-94 (in Chinese)

26. GB 50068-2001 (2001) Unified standard for reliability design of building structures. China Architecture \& Building Press, Beijing, China (in Chinese)

\section{Publisher's Note}

Springer Nature remains neutral with regard to jurisdictional claims in published maps and institutional affiliations. 